\title{
A Multidisciplinary Foundation of Inclusive Institutions Analysis
}

\author{
Piet Keizer \\ Utrecht University School of Economics, Utrecht, The Netherlands \\ Email: P.K.Keizer@uu.nl
}

How to cite this paper: Keizer, P. (2018) A Multidisciplinary Foundation of Inclusive Institutions Analysis. Theoretical Economics Letters, 8, 1987-2005.

https://doi.org/10.4236/tel.2018.811130

Received: April 9, 2018

Accepted: July 28, 2018

Published: July 31, 2018

Copyright $\odot 2018$ by author and Scientific Research Publishing Inc. This work is licensed under the Creative Commons Attribution International License (CC BY 4.0).

http://creativecommons.org/licenses/by/4.0/

\begin{abstract}
In contrast to prevalent institutional theory this article offers a multi-motivated institutional analysis. Institutions are supposed to channel human behaviour, which is economically, socially and psychically driven, so as to maximize wealth, status and self-respect, respectively. The analysis shows that extractive institutions are the result of the irrationality and immorality, especially of the people in power. The significant reduction of these two characteristics is a necessary condition for a society to become more inclusive.
\end{abstract}

\section{Keywords}

Inclusive Institutions, Multi-Motivational Structure, (Ir)Rationality, (Im)Morality, Efficiency, Reason

\section{Introduction}

Three problems dominate human life. First, many people live under poor circumstances, and lack the capacity to improve their well-being. Second, people live in groups; most of them cannot live a solitary life. They need recognition from important others, and the higher their group is ranked, the more status the group members experience. Third, even if all of us were very rich and fully accepted their status, one problem is left. The most important element, which makes people happy, is self-respect. The Self is the most vulnerable part of a person and must be protected at all cost. Richness and prestige affect self-respect positively, but there is an independent part of self-respect, which can only be influenced by the person.

The main controversy in economic institutional analysis concerns the difference between the orthodox economic logic and the heterodox historical approach of social institutions. After having discussed shortly the differences be- 
tween the two strands (section two), we will explain why the dual "logic versus history" is flawed (section three); they need each other when explaining the evolution of institutions. In a fourth section the three primary forces, which steer human behavior are discussed. It gives us three mechanisms of allocation of human energy: market, arena, and mind. When integrating the three models, we have constructed an analysis, which is far more realistic. In section five the historical approach to the evolution of institutional frameworks will be discussed. We will see that the "structure versus culture" dilemma can be solved by the introduction of the concepts psyche or mind, psychic culture or mentality and psychic institutions. In section six we make a distinction between $\alpha$-, $\beta$-, and $\gamma$-technology. The first type means know-how with respect to philosophy, logic, mathematics, language and history. The second type is about natural processes, such as physics and chemistry. The third type refers to the know-how on human behavior. It will be explained why an inclusive society needs more progress in $\alpha \gamma$-technology-which means growing reasonability, to "accompany" the ongoing progress in $\alpha \beta$-technology. In section seven we draw some conclusions.

\section{A Short Review of the Literature on Institutions}

As we said in the introduction the literature on institutions shows that the orthodox approach stresses economic logic, while heterodoxy focuses on a historical approach on societal institutions. The New Institutional Economics (NIE) [1] [2] is founded on orthodox economics, which assumes the economic motivation being the only one relevant. The Original Institutional Economics (OIE) [3] [4] considers institutions as social phenomena, but is not explicit on its motivational foundation. People adjust to circumstances, period. The third aspect is absent in the institutions literature: persons do not exist, and societies do not have a mind, there is no collective consciousness and no willpower, neither conscious nor unconscious. It implies that strong personalities do not play an important role in the course of history. The only serious debate is that between the structuralists and the people who consider culture as a leading variable. NIE uses the orthodox economic logic as its theoretical foundation. Economic structure is decisive for the economic performance. OIE, however, pays barely attention to motivation and its consequent logic. In contrast to that, it pretends to offer a historical/evolutionary approach to institutions. In some cases structure is decisive [5], and in other cases-such as the contributions of Smith (1759), Weber [6] and Sen (2002) - it is culture, which determines economic performance.

In this article I will show that the duals "logic versus history", and "structure versus culture" are counter-productive. In both cases there is a strong interaction between the two. I will also show that the dual "economic versus social" is a bad one. Human behavior is driven by three primary motivations, which are the economic, the social and the psychic one. They play their role simultaneously, always and everywhere. The relative weights of the three forces, however, can gradually change over time and can differ over various cultures. 


\section{Logic versus History}

Orthodox economics can be interpreted as economic logic. It is based on a number of axioms, and it contains a series of logical implications. The axioms are: actors are economically motivated (1), they are perfectly rational, which means having perfect self-control (2), they are atomistic, which means that also relationships between humans are of an economic nature (3), and the actors lives in a reality which is so mechanic and determined, that it can be described by means of logic and mathematics [later we came back to these axioms]. It leads to a number of relationships between variables, which show the functioning of the economic (market) mechanism. A market economy as a whole is considered as the aggregate of all micro-markets. This so-called economic world is determined, mechanic, and closed. The system is supposed to be in equilibrium. If we allow shocks from outside the economic world, there is temporary disequilibrium. The system of markets is a stable system, as long as there is no government, which intervenes into the process of price formation. Price adjustments drive the system in the direction of equilibrium. So, disequilibria will always remain small. Governments are only useful in protecting property rights.

Heterodox economics rejects the strategy of constructing an economic world. The gap between the economic and the real world is fundamental and cannot be bridged by relaxing one or a few axioms or other assumptions. Therefore, heterodox economists make a different start. They experience a complex world, in which groups of people have developed institutional frameworks, thereby reducing their uncertainty about what will happen in the future. Without some predictability it is impossible to make plans and to behave rationally. Progress requires rules of behaviour, which are accepted by a large majority. But even then reality is still an open system, and mechanisms are difficult to discover because of the organic and evolving character of reality. Moreover, reality is reflexive, which means that it changes as soon as new knowledge is applied. In this world the slogan "never change a winning team" is a bad one-circumstances are permanently evolving.

Because there is hardly any debate between orthodox and heterodox economists, this methodological divide has not been solved yet. Nevertheless, it is easy to see how we can overcome this conflict. Essentially there is nothing wrong with the orthodox construction of an "economic world". It only pretends to be "economic logic". Orthodox psychologists could decide to construct a "psychic world" and orthodox sociologists could make a "social world". By integrating these isolated abstractions, we have made a more realistic construction, compared with the three isolated worlds. Neuroscientists could make a world, which reflects our brain. Health scientists could construct world, which only reflects a human body, and environmentalists could construct a simple model of (living) nature. Technological progress of a $\beta$-nature can help us solve the economic problems. Technological progress of a $\gamma$-nature can help us solve the psychic and social problems. Both types of technologies need well-thought philosophical and 
analytical foundations, which give us the language in which we can usefully discuss practical problems. In other words, we need technological progress of an $\alpha$-type.

Philosophy offers us knowledge, which is necessary when constructing paradigms. According to Lakatos, a well-founded research programme leaves its philosophical basis unchanged for a long time [7]. Concepts are well-defined and function as the (constant) substance of an analysis, while the properties of these substances might permanently change over time ${ }^{1}$.

In this way we have given our complex world a structure, in which main concepts, such as economic, rational, social, physical, chemical, neural, mental and logic have a fixed meaning. The properties, however, are all variable.

Heterodox economics starts with the axiom saying that we live in a complex world, which cannot be interpreted without adopting a number of simple rules of behaviour first. Primitive people are inclined to declare very important things being sacred, so as to please their gods. Moreover, they "build" clan structures: hierarchical and simple. In earlier times men hunted animals, and women gathered edible plants and took care for the children. Over time technological progress of the $\beta$-type led up to more sophisticated methods of production. Technological progress of the $\gamma$-type led up to more reasonable cultures. Monotheism functioned as a barrier to ongoing group rivalry. The idea of God as the source of love has contributed significantly to more harmonious relationships. The U.N. Charter is clear: every person counts. Further progress can be made in formulating animal rights, biodiversity and the idea of responsibility for the planet as a whole. Moreover, we need to bridge the gap between cognition, expressed in thoughts and texts on the one hand and emotion or motivation, expressed in concrete action on the other hand.

So, history plays an important role in heterodox approaches. But history cannot be observed and described without an explicitly formulated paradigm and analysis. In which language do we tell our stories? The NIE offers a neoclassical history, while radical economists are telling a completely different story. Weber, an economist, who became a giant in sociology, has largely and significantly contributed to economic history. While in neoclassical and radical-economic stories rationality is a constant, makes Weber this concept to the core varable in his explanation of historical development. In other words, a historical approach cannot do without logic. The idea of historical logic is not enough-that's just about the effects of the past on the present, and the effects of present expectations on the future. So, the historical approach is essentially about the influence of time. But history is more; it needs one or a few logics, fixing the language used to discuss the content of human behavior, besides the aspect of time. And here the role of the economic, the psychic and the social aspect comes into the analysis. The conclusion is that there is no contradiction between logic and history. On the contrary, they are perfectly complementary. And so with the concepts

${ }^{1}$ The concept "change" in properties is only meaningful in a context of fixed substances. 
economic and social: they refer to two different motivations and mechanisms, which operate simultaneiously, always and everywhere. It also means that there is no structure without culture. Institutional analysis is the field, where the ongoing interactuoin between mind, culture and structure must be studied: again, never one without the others.

\section{Three Mechanisms of Allocation of Human Energy}

We start our analysis of the economy with three axioms. The first axiom is "there is reality". Since we want to know more about human behavior, we make a distinction between human and non-human elements. We continue with an analysis of humans, thereby making a distinction between three primary relationships [8]:

1) The relationship between human and non-human elements; taken from the point of view of humans this relationship represents the economic aspect. If some humans are considered as "commodities" by other persons, these humans must be considered as non-human; slaves, for instance.

2) The relationship between different (groups of) humans; it represents the social aspect.

3) The relationship between a person with his Self. This is the psychic aspect.

The second axiom is "reality is energy". We make a distinction between human and non-human energy. Energy is scarce and the possession of it means power, which can be used to level barriers. Natural energy gives us light, heat and motion. Human energy gives us the power to reach principal goals-by means of channelled energy. Technology of the $\beta$-type makes economic relationships more efficient. Technology of the $\gamma$-type makes the psychic and social relationships more efficient. As explained in the introduction $\beta$ - as well as $\gamma$-science need an $\alpha$-foundation. Therefore, we will use two types of technology, namely $\alpha \beta$ and $\alpha \gamma$, thereby emphasizing the relevance of paradigm, language, including mathematics and analysis for scientific and technological development.

A third axiom says that every element is restlessly seeking for balance (homeostasis). We can also say that everything is permanently searching for an optimum, which means a maximum of comfort. This balance will never be reached, because of the permanently changing circumstances of the elements.

Orthodox economics is about scarcity of natural resources. One of the most important goods is knowledge. Lack of brain capacity makes it impossible to have a complete and perfect model of reality (Simon, 1957). A model is necessarily an abstraction from reality. From an imperfect stock of information a person must build a logically consistent structure, which is called knowledge. A well-formulated paradigm has the function of holding information together in a particular form or structure. The framework of thought, which people have in mind is an example of perhaps the most important institution [3]. It helps people develop rules of behaviour, which make their lives more efficient. The framework of thought interprets human experience. Over time humans automatize particular responses on particular impulses on the basis of such a frame- 
work; these rules also are an important part of human institutions.

Institutionalized behavior might be based on mistakes, because of misinterpretation of the situation, or because of significant changes in the circumstances, for instance. Historical events, be it your father died because of lung cancer, or a global financial crisis, can trigger humans to evaluate their $\alpha \gamma$-knowledge and change their behavior. In the first case, the reaction might be to stop smoking, but it is also possible that the reaction is based on a completely new idea about life style.

Institutions are meant to channel behavior. Therefore, it is necessary to know which are the primary forces that set people in motion. As we have clarified, these are the economic force, which drives us to reduce scarcity of natural resources as much as possible (1), the psychic force, which drives us to maximize self-respect (2), and the social force, which drives us to maximize social recognition or status (3).

\subsection{The Economic World}

Orthodox economics analyzes and models this world, in which the economic force is the only driver of human behaviour. Some persons or organizations combine needs with resources, and operate as demanders on markets. Others do the same, and operate as suppliers on markets. They meet each other, and demanders look for the lowest price, given the quality of a particular good, while suppliers look for the highest price. In processes of higgling and bargaining the market price is determined. Market power determines the price level. In case of perfect competition, the market price is the perfect expression of the natural scarcity of the goods that are transacted.

Market participants are driven by the economic motivation only. To get rid of the psychic motivation actors are assumed to be perfectly rational. To abstain from the social motivation actors are assumed to be non-social, or atomistic. It means that all relations between people are assumed to be of an economic nature. This paradigm of the homo oeconomicus has led to the analysis of markets in terms of supply and demand, as we know from textbooks. Price flexibility leads to markets always being close to equilibrium. A market economy is a stable system; disequilibria are so small that actors establish their decisions of spending and saving on the basis of trends rather than on actual values. It means that recessions are small and economies function well without discretionary government intervention. In Figure 1, we have pictured the mechanism of a market. A represents supply, V represents demand, $\mathrm{P}$ is the price level, and $\mathrm{Q}(\mathrm{V})$ and $\mathrm{Q}$ (A) are the quantity demanded and the quantity supplied, respectively. In Figure 2, we have presented a picture of the functioning of a market economy. All markets are so small relative to the whole of the economy, that not any market disequilibrium is able to make the economy unstable ${ }^{2}$.

${ }^{2}$ The money market is generally considered to be an exception. An independent monetary authority should adopt the rule that the money supply grows proportional to the trend in the volume of production. 


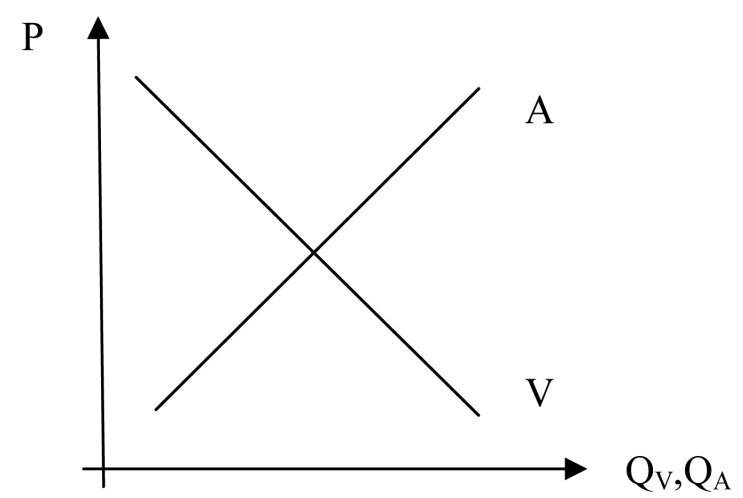

Figure 1. The economic (market) mechanism; source: Keizer (2015).

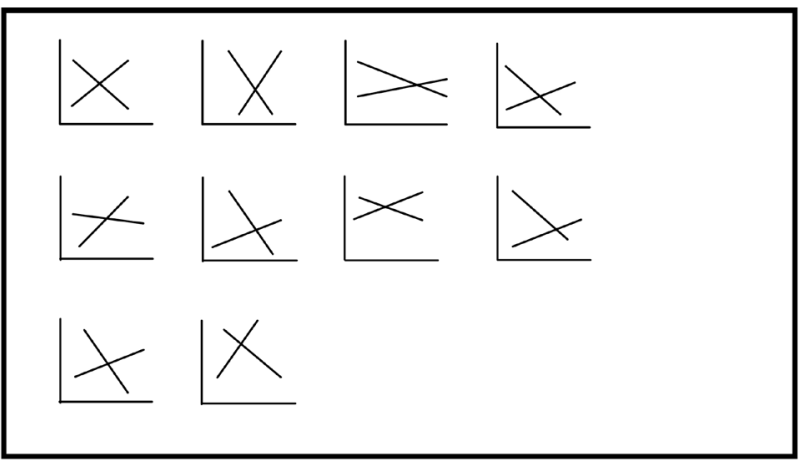

Figure 2. The economic mechanism of a market economy; source: Keizer (2015).

A free market economy might need a government to protect private property rights. In neo-Austrian and libertarian circles some economists work on the basis of the idea of a society without government. Everything has a private owner, who is responsible for the protection of his property-if necessary by means of private police and private armies.

Perfectly free market economies do not exist in real life. Institutions emerge, which make the economy more efficient. According to orthodox economics only institutions that do not hinder the functoning of the price mechanism might be efficient. Institutions that regulate prices and prescribe conditions with respect to labour, quality of the goods and financial buffers, are considered inefficient.

Given the preferences of the people and the amount of resources available, economic growth results from $\beta$-technological progress, channeling natural and human energy increasingly efficient. For citizens with enough money there is ample place in a market society. For poor people there is family and charity.

The economic world is a thought experiment. In this world actors are inclined to set up a public system, which aims at the protection of property rights. Lack of moral awareness makes it difficult, but rational people might accept a tough system of monitoring and penalizing the bad guys. But even that tough system corroses because of a lack of morality. The same holds for other types of spontaneous institutions, as analyzed by the NIE, such as the design of private contracts, in which transaction conditions are described. 


\subsection{The Psychic World}

Orthodox psychology analyses the mind of a person, who is rich and socially recognized [8]. So, he has no economic and social problems; the only problem is his psychic problem, which is a lack of self-respect. The analysis of this problem starts with the assumption that there are three elements in the mind-system. There are an " $P$ ' and two selves. The ' $I$ " is the decision-maker, who is equiped with intuition and willpower, and uses this power to make the person's behaviour more rational. The first self is called the actual self. It is a bundle of emotions, that drive people to behave so as to maximize short-term self-respect. Behavior is a combination of automatized and spontaneous behavior and reactions on sudden impulses. Comfort is the goal-then the person regards himself as successful, and therefore respectful. The second self is called the true self. When persons grow in wisdom they increasingly observe their inner world. This is called introspection, and is, together with observations of the external or empirical world, the most important source of knowledge. The true self judges the actual self. As long as there is a large difference between the actual and the true self, there is a inner or psychic tension. It creates negative feelings about the "I", who apparently fails to manifest his true self. Low self-respect must be veiled, since its discovery by the "I" is expected to be a disaster.

Now we have two strategies to become more rational in the eyes of the "I":

1) Use willpower to reduce the difference between the actual and the true self. If the person discovers that he is weak, he can decide to invest in the production of more willpower. It all should lead to more control over the actual self.

2) Open the mind for inconvenient information. Our mind is filled with cognitive structures. If new information does not fit existing knowledge structures, there is a mechanism, which blocks this information [9] [10]. So, if a CEO did a good job, and all colleagues have praised him for that, new information, making clear that his performance was actually very bad, will be denied. It makes the person very angry with the person who spread this new information; a new conflict is born, mostly ending up with the firing of the messenger. A more rational person is able to break through this ostridge behavior.

So, humans are irrational, and some are more irrational than others. The logic of the psyche describes how the mental mechanism works. We call it the ostrich-mechanism, referring to the habit of ostriches to put their head into the sand in case of danger. When we know the functioning of the mind, we also know how to reduce irrationality. It means that people of good will are able to become more rational, which is at the long-run benefit of the person, and very beneficial for economy and society at large.

In Figure 3, we have presented a picture of this mechanism. Irrational people profit from short-term benefits, but do not release their omni-present psychic tension. It is housed in the unconscious, but takes energy to keep the inconvenient information unconsciously. These people do not make progress in the discovery and manifestation of their true self, and keep applying $\alpha \gamma$-technology of a 


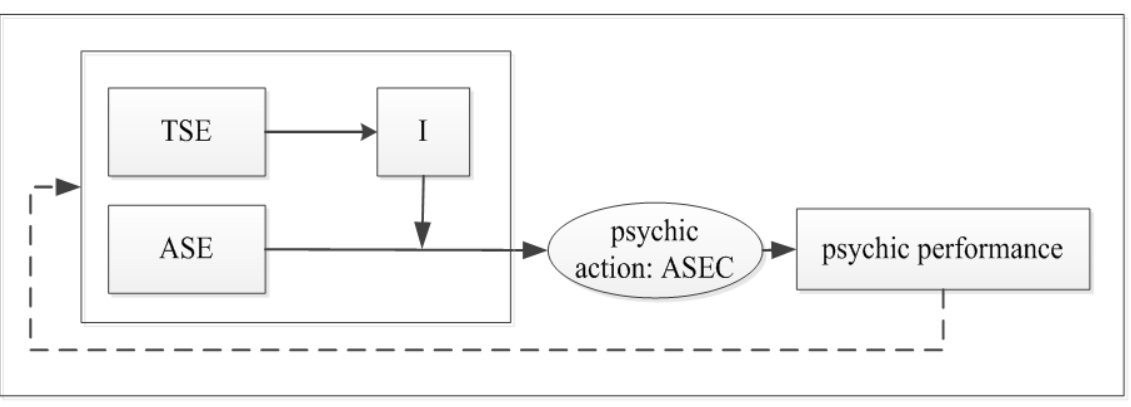

Figure 3. The psychic world.

primitive level.TSE refers to the true self as experienced by the "I", ASE means the actual self as experienced by the "I", and ASEC refers to the actual self as experienced ànd controlled by the "I".

In case of strong irrationality psychic institutions barely develop. Many people are addicted to alcohol or sugar, which has a negative effect on their functioning. Important people keep denying hard and difficult-to-deny facts. Organizations can help people to become more rational, but unfortunately many lack the willpower to adopt their strategies. More sleep, regular breaks, less noisy environments-it all can help people to become more relaxed and productive. But these kinds of effects are systematically ignored by irrational people.

\subsection{The Social World}

Orthodox sociology assumes an actor is a homo sociologicus. He is rich and acts perfectly rational. There is only one problem: he is not satisfied with the amount of recognition he receives from relevant others. Even living in a world in which all men are equal-having the same level of recognition-does not satisfy him. He wants to be superior to others. How to develop a status yardstick, which makes him and his group to the number one in his world? Subsequently other groups must be convinced of the superiority of his group. He wants his group to be considered as the ruling elite, including all sorts of "natural" privileges.

The mechanism, which rules the social world is the mechanism of the scape-goat. It runs as follows. Suppose there are two groups, which consider each other as their principal rival. It can be the older versus the younger brother in a family, or rivalry between two families. It can be two departments of a firm, and rivalry between countries. At the moment the real world is the arena of the rivalry of three worlds: the American versus the Russian versus the Chinese world. Rivalry is omnipresent, but the energy that people spend to increase their status, is a variable across places and over time. Assume group A is working hard to improve its economic performance. Group B discovers it, and reacts on this "threat" by increasing its homogeneity. It makes group B stronger and therefore economically more successful. If status primarily depends on military power, economic success makes it possible to buy and produce high-quality weapons. But artistic performance might also contribute to the status of a group or country. 
Heterogeneity makes a group weaker. In a democracy, in which each person counts, it is more difficult to react swiftly to eventual threats from the outside. In that case the diversity in the group must be reduced, and the easiest way is to throw out critical persons, strangers and members, who were member of the enemy in the past. These people are not trustworthy in times of "war". If it is impossible to throw these people out, they must be suppressed. Some persons have become the no-good of the family. Some employees are fired because they discovered fraud by top managers. Some politicians are thrown out of their party, since they were too serious in fighting against the local mafia. Scape-goats are punished in the expectation that it leads to a homogeneization of the group, and consequently to a higher position in the ranking ${ }^{3}$.

In Figure 4, we have pictured the social mechanism, which determines the ranking. Fear for total destruction have triggered moral capacities. In primitive societies people lived in small groups. There was barely any room for individuality. Regularly different groups fought for the ownership of land. The leadership of the clan or tribe was responsible for the cohesion. Especially in times of war people were remembered of their moral duties-"keep the institutions, necessary to survive and rule the area". Fevre calls this institution "ersatz morality": rules of a moral kind, meant to serve the interests of the group [11]. If necessary killing members of the other group, is a moral good, not a bad. Under the influence of the New Testament of the Bible, Plato, Kant and the United Nations a different idea of morality developed. Here morality is not linked to a group, but to humankind as a whole. On the basis of "being member of the group of humans" we attach a number of inalienable rights and duties to every human. It does not hold for virtuous people only, but also for robbers and serial killers-not any person is excluded. Fevre calls this institution "genuine morality". In the figure groups $\mathrm{A}$ and $\mathrm{B}$ are presented as a circle, reflecting their ideological space. Members are indicated with the letter $\mathrm{x}$. The radiation of the circle shows the maximum distance between a member's ideology and the core ideology that is accepted by the group. The distance between the two core positions a and b reflect the status difference between the groups. If group $B$ is able to make the difference smaller, group A reacts by making the maximum ideological distance smaller. It makes group A stronger. Of course, group B will react by making its maximum ideological distance smaller.

In the social world rational and social actors are inclined to develop social institutions. The rationality of the social actors, combined with the typical social behaviour of grouping and ranking, leads to a rational status battle without end. If genuine morality grows-the threat of total destruction might function as an incentive to limit the battle-some persons, member of a fighting group, might become less loyal, and discuss the problem with members of the opponent. In this way morality becomes a little more genuine. Institutional change accompanies this growing purity of their morality.

${ }^{3}$ The term "scape-goat" refers to a jewish ritual. When there were rows creating disintegration, the priests sent a goat into the desert, with his death as the intended consequence. For the struggling parties it was a message from JWH (the God of the Jews): stop the fighting. 


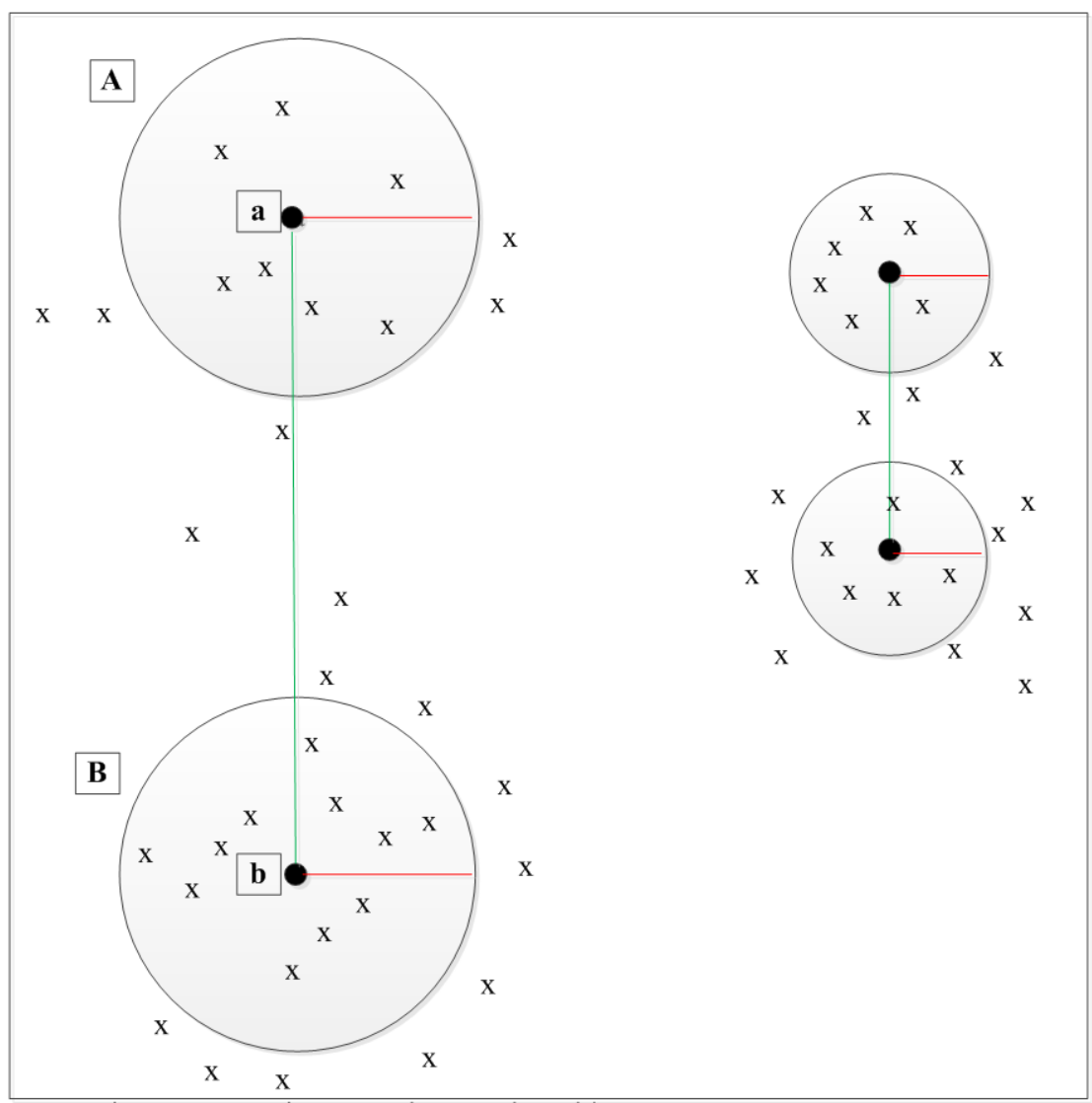

Figure 4. the arena-mechaism in the social world; source: Keizer [8].

Today many people in the world apply "ersatz morality" rules, and also Western countries, which commit their selves to "genuine morality" in official documents, act quite immoral. Social policies, which aim at an increase in the degree of genuine morality might contribute significantly to a more prosperous and just society, ruled by more inclusive institutions.

\subsection{Welcome to the Real World}

The three worlds, just discussed, are isolated abstractions. A real world perspective accepts no abstractions from important aspects. It takes all relevant aspects into account, and abstracts from details only. In Figure 5, we have presented the three primary aspects in one picture. Every real action is the result of the simultaneous operation of the three primary motivations. It means that the real world will never show the operation of one of the three allocation mechanisms. The relative weight is context-dependent. Some real markets are highly competitive, and their functoning approaches the description as given by orthodox economics. Other real markets are not competitive at all. In economic sociology many examples of real markets are discussed, that are almost pure arenas, where social status battles dominate the relationships between groups. Very often a group contains private as well as public actors-a phenomenon that is systematically ignored by neoclassical economics [12]. 


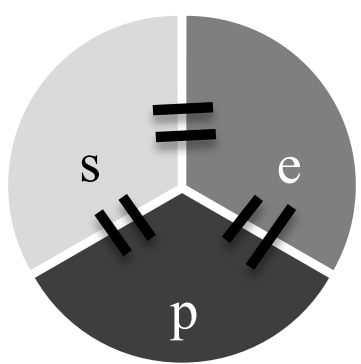

Figure 5. The three aspects of human behavior; p: psychic world; e: economic world; s: social world. Source: Keizer [8].

In this real world different types of institutional development can be imagined. Irrational landowners might see their workers as an opportunity to be exploited. They are poor and powerless, and accept very low wages. The landowners are rich and have developed good relationships with the government. So, even small protests are immediately suppressed. This unequal power relationship makes it difficult to break through the barriers of irrationality and morality. In some countries small and medium-sized enterprises might come up. The entrepreneurs have a different relationship with their workers. Because of their size they also develop different relationships with the government. It might be the beginning of a transformation of extractive towards more inclusive institutions.

In Northern Europe-far away from Rome-many of these small business people resisted against the Roman-Catholic Church. They protested against the abuse of power by the clerical elite, and started their own churches. Luther translated the Bible into German, making it possible for the individual members of the Church to read the Bible themselves. So, many learned to accept individual responsibility for their actions rather than just obeying the rules by the elite. In the eyes of God every person counts (in the New Testament of the Bible God is inclusive!). Nowadays a significant number of North-European persons feel committed to this rule: every person must bear responsibility for himself by adopting psychic (!) institutions, and every person is member of society at large, thereby co-responsible for the construction of a just society, in which every person counts. Southern Europe shows less inclusive institutions, and so with many other areas in the world.

Institutions could be presented as attempts to create an extractive or an inclusive society. In every society there are forces, which drive society in the "extractive" direction, there by clustering power in the hands of a few irational and immoral people. In every society there are also forces driving society in the direction of inclusion, which implies more rationality and morality.

In the following section we will discuss the historical approach and show why it needs a so-called "logical approach".

\section{Economic History of the Rise and Decline of Institutions}

In this section the central question is what we can learn from history. Orthodox 
economists interpret historical development from an economic world framework. Their approach is called NIE, and they see technological progress of the $\beta$-type as the prime driver of development. It can be restrained by anti-progressive institutions. A well-functioning system of private property rights guarantees economic growth. Inequality is unavoidable, but a rich elite has the incentive to continue investing resources until every potentially productive worker has a job. A market economy produces its own institutions spontaneously. As long as the government sticks to its own task-protection of private property by means of a system of justice, including an army and a police force-the economy will grow forever.

An orthodox sociological approach is offered by Girard [13]. History is about the human attempt to get control over the panta rei-the omnipresent mimetic desire, which drives people to the most violent actions. If John is the most prestigious person in a particular group, other members will imitate him, so as to reduce the status difference. If John falls in love with Anita, his rivals also fall in love with Anita. If John wears particular shoes, the other guys want these shoes too. This mimetic motivation is a prime driver behind many economic and political conflicts, making them difficult to solve. According to Girard rivalry of this type can only be reduced if an increasing number of people discover this mechanism, and change their behavior. It means technological progress of a $\gamma$-type. Social leaders-highly esteemed people-hate the guys who stop rivalling-they need people to be beaten. The most important function of institutions is to reduce the strength of the mimetic desires.

Marx offers a sociological approach of a different kind. Economic development is driven by $\beta$-technology, and the economic structure which emerges determines the social structure, which is characterized by class conflict. In a feudal system feudals rule society. Peasants are dependent on these owners of land. Technological progress means that different economic groups become more powerful. History shows that merchants, and later manufacturers-capitalists, took over political power. According to Marx humans are inclined to cooperate and to sympathize with each other. But as long as the economic structure implies class conflict, society will also be characterized by social conflict. It leads to wars, since the capitalists need cheap raw materials from undeveloped countries. If global production has reached a level, that makes it possible for all to have a decent living, it makes sense for the workers to make revolution. If successful they install communist institutions. Since human nature is cooperative rather than exploitative, these institutions will be inclusive.

Weber describes historical development in terms of increasing rationality (Weber, 1904). While earlier civilizations were characterized by tradition, is modern society ruled by rational procedures, such as bureaucracy. He makes a distinction between value-rationality and instrumental rationality, and he fears that the future will be dominated by instrumental rationality. Analogous to Fevre we call this ersatz rationality, in contrast to value-rationality, which can be 
called genuine rationality.

Van Bavel [5] analyzes historical development in terms of economic and social structure. When societies deregulate factor markets wealth distribution shows increasing inequality. It leads to social strife, which affects economic productivity negatively. There is a very long-term cycle of boost and bump, taking many centuries. The crisis of 2008 illustrates this idea, and makes clear that it might be the beginning of a very long period of stagnation.

Do institutions offer individuals room for individual responsibility and initiative and do they offer people justice? If yes, do persons really take their responsibility? The concepts "rationality" and "morality" play a pivotal role in answering these questions.

The approaches discussed answer the question of what are the true events and developments that determine the course of history. Are they technological innovations of a $\beta$-type (control over fire, birth control, robots) or are they technological innovations of a $\gamma$-type (the lessons taught by Jezus and by Luther, for instance). The answers are logical implications from the perspectives taken. But it is important to ask what is a typical historical perspective, besides the economic and social perspectives. The evolutionary approach gives an answer.

Original Institutional Economics (OIE) is characterized by its evolutionary perspective. The term "economic" does not refer to the economic aspect of human life, but to the real-life economy, and so with the concept "social", which refers to real-life society rather than to the social aspect of human behaviour. It studies the way economies evolve over time. The growth of knowledge is decisive and the most important institutions, which block progress are the habits of thought [3]. In primitive societies traditions determine human behavior, and novelties are not discovered, because nobody has the open mind, which is necessary for discoveries. Particular events can trigger people to change their attitudes. After a bloody war some people might react: "never a war again", while in the past people always reacted: "how shall we take revenge?" The first group might ask the question of how to keep peace, which is a typical $\gamma$-technological question. The second group might ask the question of how to make their weapons more efficient, which is a typical $\beta$-technological question. Growth of knowledge leads to new and different experiences, which make the new world incomparable to the old world. We can never return to the old world, because of the different content of the minds of the people, in the cognitive as well as in the emotional sense. If we discover that the new ways of thinking and acting are creating one failure after the other, we cannot turn back, only go forward and try to learn from our mistakes. Because of our irrationality we don't want to accept serious mistakes. It means that we continue our trip and stubbornly belief that in the end all will be right. War after war, and one economic crisis after the other-they do not make us wiser. The technique of warfare, however, becomes increasingly sophisticated. We keep blaming the other, and protect ourselves against critique. 
This is the typical historical or evolutionary approach: circumstances are changing all the time, and humans should adapt their behavior (not their motivation!) to these changes all the time. Those who do not sufficiently adapt, do not survive. Others persist. Evolutionary analysis has given us the concepts to think about evolution: novelty, path-dependence, hysterisis, locked-in, etc. Later evolutionary economics emerged as a separate discipline. It is very critical towards orthodox-economic and neoclassical methodology. But both branches stress the relevance of $\beta$-technology, thereby ignoring the role of $\gamma$-technology. Keizer [8] extensively discusses orthodox-economic and heterodox-economic analyses, and shows that economics need contributions of psychology and sociology. Especially the combination of psychic and social-factors is playing an important role in answering the question, under which circumstances societies tend to extractive or to inclusive institutions. In the next section we will discuss this issue.

\section{The Necessary Balance between $\beta$ - and $\gamma$-Technology}

Human progress is based on permanent improvement of the quality of our knowledge. Orthodox economics, including NIE, is based on the axioms that humans are perfectly rational and non-social. In other words, we all have perfect control over ourselves and we approach each other only in economic terms. Social problems do not exist. It is logical that in this economic world only technology of the $\beta$-type plays a role. It makes that economists always stress the relevance of $\beta$-science, independent of its mental and social context. This article pays attention to the role of irrationality and immorality, as defined in Section 3. The quality of life can be increased by making ourselves less irrational and less immoral. The technology necessary is or should be delivered by $\gamma$-science, especially by economics, psychology, and sociology. This section deals with the question of the relationship between the different categories of science: $\beta, \gamma$ and $\alpha$.

Imagine that $\beta$-science develops in the context of a primitive society. Every tribe is constantly honouring their gods, and consider the gods of other tribes as devils. Members of the tribe convince each other that their gods want them to kill as much members of rival tribes as possible-that would be a victory of the gods over the devils. In exchange for this victory the gods will bless their people. The way people kill the enemy becomes increasingly sophisticated. Total destruction will definitely be the end of humankind. Girard extensively researched primitive cultures. He discovered that in less primitive cultures older generations tell the younger ones of the necessity of being reluctant in always and immediately taking revenge in case of a conflict. "We shall not do that"-a moral rule, not only applied to members of the same tribe, but also to other people. Girard considers this as the beginning of human civilization [8] [13]. In the Jewish-Christian-Humanist tradition we see an evolution of this idea. Abram came with the idea of monotheism; there is just one god and he loves the Jews: we are the Chosen (Old Testament of the Bible). The Jew Jesus advocated the view that 
God loves all his creatures-no-one exepted. Humanists don't like to talk about God, and stick to the idea of humans being responsible-for humans, animals and plants alike.

Now the question is whether we can reach such a level of love for ourselves ànd for our neighbors, that we can develop and use extremely sophisticated $\beta$-technology without the fear for abuse. Nowadays North-Korean leadership considers almost all other countries as their enemy, and that's the reason why they develop nuclear weapons. Russia is born again, and tries to rebuild a so-called Russian world-if necessary with the most-advanced $\beta$-technology. They hack computer systems in rival countries, and intervene secretly into Western media. The financial crisis was the result of globalization, computerization of the financial world AND of a large amount of people, who could know that their behavior made the system increasingly fragile. Too many kept silent and functioned "well" in a bad system. Where were the reponsible moral and rational people? Where was the Weberian value-rationality, which should direct the software of the global systems into pro-social direction?

In order to see the relationship between $\beta$ - and $\gamma$-science, we need an understanding of $\alpha$-science. Only then we can compare and contrast the two branches. $A$-science contains disciplines such as philosophy, logic, language, and history. Actually it is about the basics of everything. $B$ - and $\gamma$-science are specifications; the first is about the natural environment, and the second is about life, about vitality, as expressed by plants, animals and humans. When studying $\gamma$-science students need $\alpha$-knowledge in order to know how to start a particular analysis. By means of philosophy, logic, and history a paradigm can be constructed, and a disciplinary language developed. Orthodox economics, orthodox psychology and orthodox sociology are beautiful examples, but unfit to function as an analytical basis for empirical research. First, an integrated logic should be constructed-see Section 3 of this article-and next a general history should be told [8]. Only then empirical research can deliver more specific and particular stories. $\Gamma$-researchers should stay in contact with $\alpha$-scientists: both groups can profit from the results of the other group. The same story can be told about the interrelationship between $\alpha$ - and $\beta$ - and between $\beta$ - and $\gamma$-science. In Figure 6 , we have pictured the interrelationship between the various scientific disciplines.

$\Gamma$-science is about the behavior of living creatures. We focus on the humans. There are two important epistemologies. The first is introspection or observation

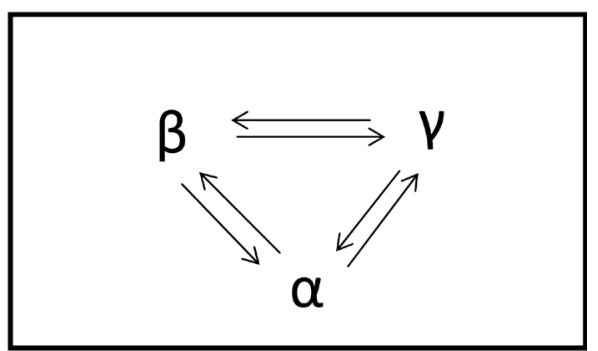

Figure 6. The interrelationships between $\alpha$-, $\beta$ - and $\gamma$-science; source: Keizer [8]. 
of the mind, which is the inner world. The second is empirical observation or observation of the outer world by means of the senses. Understanding human behavior requires knowledge of the interrelationships between the two worlds.

Introspection shows that the mind is the habitat of our emotions and feelings, and our thoughts. Orthodox psychology is about the inner communication between the different parts of the self. This discourse is only about the inner tensions. The actual self behaves quite automatically and the true self always deliberates. As long as the person is not aware of any lack of self-respect, he feels comfortable. But if the situation changes, he must react, so as to maintain self-respect. He changes his behavior, or he blames others for particular losses. In this way he keeps his inner world in balance.

But this is not a real-world balance. The analysis so far is an isolated abstraction, and propositions hold under the ceteris paribus condition. Now we place the inner conversation in a social context. So, persons start a discourse with other persons. If these persons are member of the same group, the conversation will be relatively smooth. If two neoclassical economists talk with each other, they exchange information, talk about a few private matters, and continue with their work. If a neoclassical economist meets a post-Keynesian economist, they make a few polite statements like "nice meeting you", and finish the conversation before it started. In this way the long enduring conflict between the two groups endure. Decisions about educational and research programmes are taken by neoclassical economists, since they have the power. Hiring of staff-members is also a neoclassical affair. Their journals are leading, and people who have knowledge of both perspectives are small in number, and do not play any role. The neoclassical monopoly has created many problems with the economy, but irrationality of the leadership makes that these problems are not solved, but interpreted as "typical for complex systems".

In all professions this problem of growing specialization and subsequent rivalry exists. Durkheim (1899) saw this problem as typical for a modern society, and developed a societal structure to deal with it. The Dutch Polder model is an example of a Durkheimian solution for a democratic society. Because of technological changes of the $\beta$-type professional structures are evolving, making rational communication more difficult. We need technological progress of the $\gamma$-type to reduce the increasing problem of irrationality and immorality.

Economics as a science is in crisis. Economists need a new story, and this story should be one of decreasing independence, and increasing communication with other disciplines: $\alpha$-, $\beta$-, and $\gamma$-disciplines. Independence should not be a characteristic of a scientific discipline anymore. Only a person can and must claim some independence, which means a discretionary room to decide upon his own fate. True independence means that an adult person does not adjust fully to circumstances. Strong willpower is needed to create some ideological distance from the core of the own group, while remaing loyal to the own ideas of what is genuine reasonability. It is essential to clarify that you are not part of the enemy, 
that you are not a traitor, even if you develop positive relationship with persons, who are member of the rivalling group. In a last section we draw some conclusions.

\section{Conclusions}

This article is about the conditions, necessary to make institutions more inclusive. One very important condition concerns the openness of the mind of people. Irrationality and immorality of persons, and of groups and organizations refer to the lack of willingness to communicate with strangers and with those who are perceived as members of a different group. Neuroeconomics has shown that humans have the inclination to ignore information that does not fit the existing frames of knowledge. This phenomenon is called cognitive closure. If irrational people group together and develop a common view on the situation-which is called subculture or "ersatz" culture-, the group operates irrationally as well. Other groups are different and a threat to the position of the own group. A strong defense is necessary, and sometimes is an attack the best defence: Pro-active policies. This process leads to social closure, and if groups are perfectly homogeneous, also in its irrationality, there are no endogenous developments, that break through this combination of psychic and social closure. Extractive institutions are the result.

In an economic-psychic-social world actors want to become richer, and adopt $\beta$-scientific research as an important strategy. The results can be used to improve the quality of the products and production methods, making labour productivity ever higher. But their irrationality and immorality leads them to implement extractive policies; too low liquidity ratios, too low wages, fraud and corruption, for instance. People who are exploited might become apathetic or develop moral resentments. They see that the winners are acting immorally-by being corrupt and fraudulous, which leads to severe strife in the end. In this way the institutions become increasingly extractive.

How to break through this vicious circle? Groups are never perfectly homogeneous. Some individual members are more rational and moral than others. Some persons have quite independent minds-they are prepared to swim against the tide. They are mentally and morally, that is reasonably true entrepreneurs. They appear able to frame their emotions in a different way. Their self-respect is not based on wealth and prestige, but on the judgment of the own functioning in society. Many people are just followers, but some are leaders. Every person must ask himself: can I be an independent person that fights in the right direction. If the answer is positive, do it! It will create a fulfilling life with a high level of self-respect.

Economic science can become an important tool for the improvement of the mentality and the morality of the people by showing the disastrous effects of unreasonable behavior. Structural change of economy and society can only be profitable if mental and moral entrepreneurs are setting the examples, to be followed by the mass of the people. 


\section{References}

[1] Williamson, O.E. (1975) Markets and Hierarchies. Free Press, New York.

[2] North, D. (1981) Structure and Change in Economic History. W.W. Norton \& Company, New York.

[3] Veblen, Th. (1899) The Preconceptions of Economic Science. The Quarterly Journal of Economics, 13/14, 1-16.

[4] Hodgson, G.M. (2006) What Are Institutions? Journal of Economic Institutions, 40, 1-25. https://doi.org/10.4337/9781781007563.00016

[5] van Bavel, B. (2016) The Invisible Hand? How Market Economies Have Emerged and Declined Since AD 500. Oxofrd University Press, Oxford. https://doi.org/10.1093/acprof:oso/9780199608133.001.0001

[6] Weber, M. (1904) The Methodology of Social Science. Free Press, New York.

[7] Lakatos, I. (1970) Falcification and the Methodology of Scientific Research Programmes, In: Lakatos, I. and Musgrave, R.A., Eds., Criticism and the Growth of Knowledge, Cambridge University Press, Cambridge. https://doi.org/10.1017/CBO9781139171434.009

[8] Keizer, P. (2015) Multidisciplinary Economics, a Methodological Account. Oxford University Press, Oxford. https://doi.org/10.1093/acprof:oso/9780199686490.001.0001

[9] McClure, S.M., Laibson, D.I., Loewenstein, G. and Cohen, J.D. (2004) Separate Neural Systems, Value Immediate and Delayed Monetary Rewards. Science, 306, 503-507. https://doi.org/10.1126/science.1100907

[10] Kahneman, D. (2011) Thinking Slow and Fast. Penguin Books, London.

[11] Fevre, R. (2003) The New Sociology of Economic Behaviour. Sage Publications, London.

[12] Fligstein, N. (2000) The Architecture of Markets. Princeton University Press, Princeton.

[13] Girard, R. (1978) Things Hidden Since the Formation of the World. Stanford University Press, Stanford. 